D:\Nsurg \Vol. 23, No. 4, Oct. - Dec., 2019\Nsurg-2.Doc Fig. 1-2 Color (A) P. 328 - 332 II

ORIGINAL ARTICLE

\title{
Frequency of Discitis in Lumbar Discectomy Patients: A Two Year Study
}

\author{
MUHAMMAD NAWAZ KHAN, ${ }^{1}$ M. ALI NOMAN, ${ }^{1}$ RIAZ-UR-REHMAN ${ }^{2}$ \\ SAJJAD ULLAH, ${ }^{2}$ ATIYA NASIR, ${ }^{1}$ SHAHID AYUB ${ }^{1}$ \\ Department of Neurosurgery, ${ }^{1}$ Hayatabad Medical Complex \\ ${ }^{2}$ Lady Reading Hospital, Peshawar-Pakistan \\ DOI: https://doi.org/10.36552/pjns.v23i4.389
}

\begin{abstract}
Objective: Aim of conducting the study was to evaluate the incidence of post op discitis in lumbo-sacral disc surgeries.
\end{abstract}

Materials and Methods: This observational prospective study was carried out in Neurosurgery unit Hayatabad Medical Complex, Peshawar for 12 months (1st July 2017-30 ${ }^{\text {th }}$ June 2019).A total of 250 patients operated for lumbar disc surgeries were enrolled in the study, both genders and age range of 16-60 were in inclusion criteria.Patients with co-morbidities e.g., poorly controlled diabetics and immunosuppressed patients were excluded from the study. All patients were followed to calculate the frequency of discitis.

Results: Among the 250 cases, 11 (4.4\%) were diagnosed with discitis. 15\% cases had slight sign and symptoms, pain and surgical scar tenderness not warranting the diagnosis of discitis. The mean age in this study was 37 years with Standard Deviation of 13.769. Male cases were 133 (53.2\%) while females were 117 (46.8\%). Discitis was more common at L4-5.

Conclusion: From this data it was concluded that incidence of discitis is slightly higher in our setup than international discitis incidence/rates. The possible reason could be (to some extent) due to inefficient/poorly resourced infection prevention committee and partly due to less standardized OT system in comparison to international OT complex standards.

Keywords: Discitis, lumbosacral prolapsed intervertebral disc, Post op disc surgery infection.

\section{INTRODUCTION}

Lumbosacral disc degeneration and herniation is the most frequent reason of low backache and lower limb pain which limits one's daily activities and work. It is a common reason for which most of the surgeries are performed on lower back in young and adult population. The management of lumbar disc degeneration is multimodality starting from watchful waiting, lifestyle modification, conditioning and back muscle strengthening exercises, various pain killers/ anti-inflammatory medications, local injection therapy and inappropriately indicated cases disc surgery. There are several surgical options ranging from open surgery (full laminectomy/hemi-laminectomy/fenestration) to endoscopic lumbar disc surgery. Discitis is one of the dreadful complications of any of the surgeries of lumbar discs. It is highly resistant infection/ inflammation of intervertebral disc tissues and endplates (secondarily). Which takes months of antibiotic therapy and prolong bed rest to get cured. Discitis severe painful condition and usually do not respond to routine antibiotics. Culture and sensitivity reports usually don't show any growth in $47 \%$ of cases. $^{2}$ The histopathology features of the specimens from discitis patients often show a mixed histological picture of acute and chronic inflammation. Etiopathogenesis of discitis in post operated cases is postulated to be poor sterilization and instillation/ 
transmigration of bacteria from the surrounding operative field but sometimes it is non infectious inflammation. ${ }^{3,4}$. It is common in all ages and no gender preference is described in general.Some studies suggest male predominance as compared to female counterparts. ${ }^{5}$

As discussed earlier, tissue cultures in postoperative discitis are often sterile, but it may grow Staph Aureus, Gram Negative Bacilli, or Clastridium Perfringens. There are some rare reports of fungal infection as well. ${ }^{3}$ The diagnosis is often clinical, after an initial period of 2-4 week symptomatic relief patient presents with severe lower backache, along with persistently high ESR and CRP, there is often evidence of MRI T2 hyperintensity in the area of involved disc-adjacent endplates and vertebral bodies. The plain radiographs may show vertebral body collapse or signs of instability. ${ }^{6}$ Postoperative discitis is treated with a uniform strategy of bed rest and prolonged antibiotic regimen which includes but not limited to rifampin. Most of the patients get treated by this treatment strategy alone in a month or two except few patients who fail to respond or develop mechanical instability or an abscess. In such cases open surgery, debridement and instrumented fusion is performed. ${ }^{7,8}$ Frequency of post op discitis after lumbar disc surgeries is quoted $1 \%^{8}$ to $3 \%$ in literature. ${ }^{9}$

We are working in a poorly resourced health system where sterilization and OT setup is not upto the comparison of international standards. Yet we are striving hard to maintain high levels of patient care, both in OT and post-op. The results of this study give the actual picture of our patient care and efficacy of sterilization/disinfection/infection control mechanisms while performing surgeries on lumbar spine. These results show us the room for improvement to bring down infection rates and to design further studies to specifically identify the factors involved in etiopathogenesis of discitis in our setup.

\section{MATERIAL AND METHODS}

\section{Study Design}

This observational prospective study was carried out in Brain and Spine unit, Hayat Abad Medical Complex, Peshawar, for 12 months (from 1st July 2017 to 30th June 2019).

\section{Inclusion Criteria}

All patients operated for lumbosacral prolapsed intervertebral disc (both male and female) in the age range 16-60 years were included in the study.

\section{Exclusion Criteria}

Patients with co-morbidities e.g., poorly controlled diabetes and immune-suppressed patients were excluded from the study.

\section{Data Collection}

For all enrolled cases, standard operative procedures (SOPs) were followed for pre-op, post-op and intra-op care. Single dose IV antibiotics: Cefoperazone + Sulbactam was given to all patients at the induction of anesthesia and 5days antibiotics administeredpost operatively. 30-days follow up was done to look for any complaints of discitis. If the patient complained any sign and symptom of discitis at any follow up visit, he/she was to be subjected to extensive clinical history, physical examination, X-Ray and MRI Lumbar spine and lab tests (erythrocytes sedimentation Rate, C- Reactive Proteins levels, Complete Blood Counts). Once the diagnosis is established by senior consultant, the case has to be treated either as an OPD case or admitted to in patient facility.

\section{Data Analysis}

All data collected in pre-designed Performa. The data was analyzed through SPSS version 20, and presented in the form of charts and graphs.

\section{RESULTS}

\section{Age Incidence}

250 cases were enrolled. $69(27.6 \%)$ cases were in the age group 16-29 years, $81(32.4 \%)$ cases in the age group 30-39 years, $66(26.4 \%)$ cases in the age group $40-49$ years, $34(13.6 \%)$ cases in the age range 50 59years.

\section{Gender Distribution}

Gender distribution: 133 (53.2\%) male cases, while $117(46.8 \%)$ female cases.

\section{Clinical Presentation}

$170(68 \%)$ patients had levels L4-L5 while 80 (32\%) cases had L5-S1 involvement. Total 11 (4.15\%) cases 
had developed post op discitis while 239 (95.85\%) cases didn't had discitis. Data is presented in tables below.

Table 1: Age Distribution.

\begin{tabular}{|c|c|c|}
\hline Age Groups & Number of Cases & Percent \\
\hline $16-29$ & 69 & $27.6 \%$ \\
\hline $30-39$ & 81 & $32.4 \%$ \\
\hline $40-49$ & 66 & $26.4 \%$ \\
\hline $50-59$ & 34 & $13.6 \%$ \\
\hline
\end{tabular}

Table 2: Disc Space Involvement.

\begin{tabular}{|c|c|c|}
\hline Involved Level & Number of Cases & Percent \\
\hline L4 - L5 & 170 & $68 \%$ \\
\hline L5 - S1 & 80 & $32 \%$ \\
\hline
\end{tabular}

Table 3: Post-op Discitis.

\begin{tabular}{|l|c|c|}
\hline Discitis & Cases & Percent \\
\hline Involved & 11 & $4.4 \%$ \\
\hline Not involved & 239 & $95.6 \%$ \\
\hline
\end{tabular}

Table 4: Post-op Discitis: Age Distribution (Total = 250).

\begin{tabular}{|l|c|c|c|c|c|}
\hline Discitis & $\mathbf{1 6 - 2 9}$ & $\mathbf{3 0 - 3 9}$ & $\mathbf{4 0 - 4 9}$ & $\mathbf{5 0 - 5 9}$ & $\begin{array}{c}\text { Total } \\
\text { Cases }\end{array}$ \\
\hline Involved & 0 & 2 & 4 & 5 & 11 \\
\hline Not involved & 74 & 75 & 61 & 29 & 239 \\
\hline Total & 74 & 77 & 65 & 34 & 250 \\
\hline
\end{tabular}

Table 5: Post Op Discitis: Gender Distribution (Total = 250 Cases).

\begin{tabular}{|l|c|c|c|}
\hline Discitis & Men & Women & Total \\
\hline Involved & 6 & 5 & 11 \\
\hline Not involved & 147 & 92 & 239 \\
\hline Total & 153 & 97 & 250 \\
\hline
\end{tabular}

Table 6: Discitis Rate: Intervertebral Disc Level $($ Total $=250$ cases $)$.

\begin{tabular}{|l|c|c|c|}
\hline Discitis & L4_5 & L5_S1 & Total \\
\hline Involved & 6 & 5 & 11 \\
\hline Not involved & 162 & 77 & 239 \\
\hline Total & 168 & 83 & 250 \\
\hline
\end{tabular}

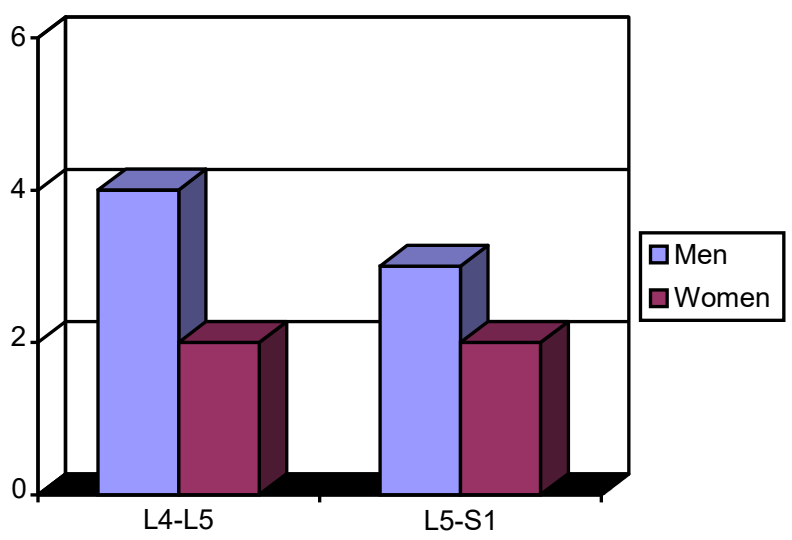

Fig. 1: Discitis rate per Intervertebral Disc level.

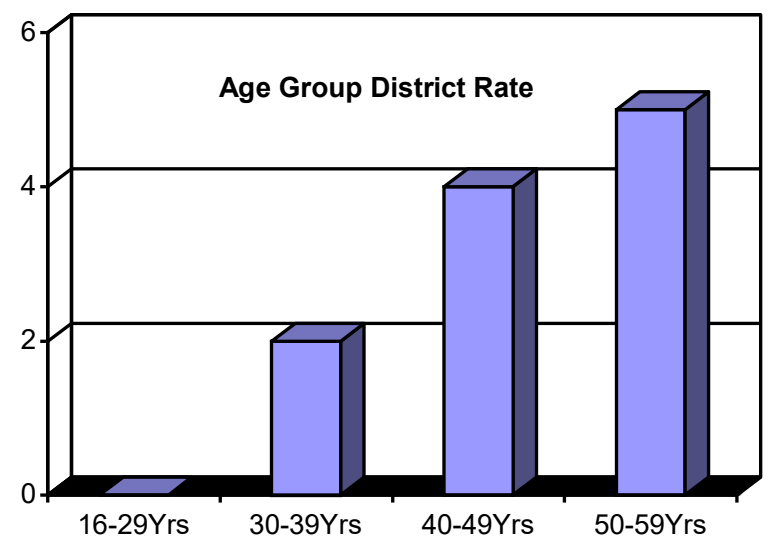

Fig. 2: Age Groups in Discitis Rate.

\section{DISCUSSION}

This study indicated that the $15 \%$ cases had slight sign and symptoms of pain and surgical scar tenderness not warranting the diagnosis of discitis. In $170(68 \%)$ cases, the level operated was L4-5 while 80 (32\%) for L5-S1. In 5 cases post-operative CSF leak was noted. The incidence of post op discitis was (11) 4.4\% .Two cases needed instrumental fixation and fusion and 9 cases were managed medically. Among the total 11 discitis cases 5 at L5-S1 level 6 at L4-L5 in which 6 were male and 4 female patients. Moreover $9 / 11$ cases 
diagnosed in cases more than 40 years age and only two patients wereunder 40 years age limit only. We compared our results with the study done by Khattak (2009) in Peshawar, Pakistan. In that study, among the 30 patients studied, only $01(3.33 \%)$ had discitis. ${ }^{10} \mathrm{We}$ observed $15 \%$ cases had a superficial surgical site infection as compared to Jolles et al that reported $1 \%$ superficial wound infection. ${ }^{11}$ We observed discitis in $11(4.4 \%)$ cases whereas Wajsfisz et al reported discitis in $2.94 \%$ cases. $^{12}$

The frequency of discitis we observed is reaching the upper limit or slightly above of frequency/ incidence reported globally. The reasons could be less standardized OT Complex/sterilization systems that we are currently working on. Cases were operated by various competency levels of consultants, individual consultant discitis rates were not calculated which could have further elaborated study results. We can conclude that the better OT setup and strict adherence to infection control mechanisms decreases postoperative discitis. We suggest multicenter randomized trial to compare the results and look for the causes.Our limitation was long term follow up beyond one month.

\section{CONCLUSION}

From our study, we can conclude that the slightly higher incidence of post op discitis may be due to the lack of international standard OT Complex and lack of adherence to standardized infection control protocols which need to be introduced urgently. Further studies are required to evaluate the role of experience of operating surgeon on the rate of post op discitis to further clarify the situation.

\section{REFERENCES}

1. Basu S, Ghosh JD, Malik FH, Tikoo A. Postoperative discitis following single-level lumbar discectomy: Our experience of 17 cases. Indian J Orthop. 2012; 46 (4):
427-33.

2. Li j, yan D, Duan L, Zhang Z, Zhu H, Zhang Z. Percutaneous discectomy and drainage for post operative intervertebral discitis. Arch Orthop trauma Surg. 2011; 131: 173-78.

3. Hamdan AT. Postoperative disc space infection after discectomy: A report on thirty-five patients. Int Orthop. 2012; 36 (2): 445-50.

4. Sharafat S, khan Z, Ali M, Azam M, Aman M. Management of post operative discitis after lumber discectomy. KJMS. 2014; 7 (1): 80-2.

5. Sheha AF. Surgical management of post-discectomy spondylodiscitis with transforaminal lumbar interbody fusion (TLIF) and posterior instrumentation. Life Sci J. 2011; 8 (4): 140-42.

6. Moon MS. Kim SS, Lee BJ, Moon JL, Sihn JC, Moon SI. Pyogenic discitis following discectomy. J Orthop Sug Res. 2012; 20 (1): 11-7.

7. Ibe MON. Surgically treated symptomatic prolapsed lumbar and sacral intervertebral discs in females: a comparative study of incidence and causative factors and treatment. Nigerian Journal of Surgery, Jul-Dec 2012; 18 (2): 61-7.

8. Nasto LA Colangalo D, B. Rossi B, Fantoni M, Pola E. Post-operative spondylodiscitis. Eur. Rev. Med. Pharmacol. Sci. 2012; 16 (2): and drainage of Infective lumbar spondylodiscitis: technique and clinical results. Clin Orthop Surg. 2012; 4 (3): 200-8.

9. Gregory DS, Seto CK, Wortley GC, Shugart CM. Acute lumbar disk pain: navigating evaluation and treatment choices. Am Fam Physician, 2008 Oct. 1; 78 (7): 83542.

10. Khattak A, Haider A, Rehman L, Mushtaq L. Surgical outcome of recurrent lumbar disc herniation: experience with 30 patients. JPMA. 2009; 23: 86-89.

11. Jolles BM, Porchet F, Theumann N. Surgical treatment of lumbar spinal stenosis. J Bone Joint Surg Br. 2001; 83-B (7): 949-53.

12. Wajsfisz A, Rillardon L, Jameson R, Drain O, Guigui P. Efficacy of repeated radicular release for the treatment of recurrent discal herniation. J Bone Joint Surg Br. 2005; 90-B, SUPPIII: 235.

\section{Additional Information}

Disclosures: Authors report no conflict of interest.

Ethical Review Board Approval: The study was conformed to the ethicalreview board requirements.

Human Subjects: Consent was obtained by all patients/participants in this study.

Conflicts of Interest:

In compliance with the ICMJE uniform disclosure form, all authors declare the following:

Financial Relationships: All authors have declared that they have no financial relationships at present or within the previous three years with any organizations that might have an interest in the submitted work.

Other Relationships: All authors have declared that there are no other relationships or activities that could appear to have influenced the submitted work. 
Address for Correspondence:

Dr. Riaz-ur-Rehman, Assistant Professor

Department of Neurosurgery

Lady Reading Hospital, Peshawar-Pakistan.

Email:drriazurrehman@yahoo.com

\begin{tabular}{|c|c|c|c|}
\hline \multicolumn{4}{|c|}{ AUTHORSHIP AND CONTRIBUTION DECLARATION } \\
\hline Sr.\# & Author's Full Name & Intellectual/Contribution to Paper in Terms of: & \multirow{8}{*}{$\begin{array}{l}\text { Signature by the } \\
\text { author(s) }\end{array}$} \\
\hline 1. & $\begin{array}{l}\text { Muhammad Nawaz Khan } \\
\text { (Main/Principal Author). }\end{array}$ & \multirow{7}{*}{$\begin{array}{l}\text { 1. Proposed topics and Basic Study Design, } \\
\text { methodology. } \\
\text { 2. Data collection and calculations } \\
\text { 3. Analysis of data and interpretation of results etc. }\end{array}$} & \\
\hline 2. & $\begin{array}{l}\text { M. Ali Noman } \\
\text { (2nd Author) }\end{array}$ & & \\
\hline 3. & Riazurrehman & & \\
\hline 3. & (3rd Author) & & \\
\hline 4. & $\begin{array}{l}\text { SajjadDawar } \\
\text { (4th Author) }\end{array}$ & & \\
\hline 5. & $\begin{array}{l}\text { Atiya Nasir } \\
\text { (5th Author) }\end{array}$ & & \\
\hline 6. & $\begin{array}{l}\text { Shahid Ayub } \\
\text { (6th Author) }\end{array}$ & & \\
\hline
\end{tabular}

Date of Submission: 13-09-2019

Date of Revision: 29-11-2019

Date of Online Publishing: 25-12-2019

Date of Print: 31-12-2019 